\title{
The Investigation of Haematuria in the Young Military Population
}

\author{
Maj H D Kumarasena, \\ MB, BS, FRCS, RAMC \\ Lt Col N E Cetti, \\ MA, FRCS, RAMC \\ Col I S Lister, \\ $M B, B C h i r$, FRCS, RAMC \\ Urology Unit, Queen Elizabeth Military Hospital, Woolwich
}

SUMMARY: The presentation of haematuria in the otherwise fit young adult is common in military practice. $\vec{\circ}$ Controversy still exists as to how fully such patients should be investigated. The findings in 90 military patients under 40. are reported and a scheme to rationalise the investigation of haematuria is put forward.

\section{Introduction}

Haematuria (gross or microscopic) as the presenting symptom or sign in the young adult continues to be a problem in investigation decision-making. Many studies emphasise the necessity of full investigation of even the minimum number of red cells seen on microscopy of the urine $^{1,2,3}$. However, as the more sophisticated examinations are both expensive and invasive, with complications of their own, the very few positive results obtained in individuals can hardly justify blanket application to all ${ }^{4}$.

In the Army the patient who presents with gross haematuria or who is found to have microscopic haematuria on routine examination is referred to physician, surgeon or urologist. The result has been in some cases incomplete investigation which misses a serious condition or conversely exhaustive tests which bring no positive results.

A study has been carried out of the patients under 40 years of age presenting with haematuria to the Army Urology Unit in the years 1980, 1981 and 1982. A flow chart of investigation is recommended.

\section{Patients and Methods}

The case notes of all those patients under 40 years of age who have presented to the Army urologists at the Queen Elizabeth Military Hospital Woolwich and the Cambridge Military Hospital Aldershot in the three years 1980 to 1982 with the sole symptom or sign of haematuria have been studied.

\section{Results}

Ninety such patients are fully documented with an age range of 8 to 40 . Table I shows the relevant findings in these patients. In Table II the details of the 11 positive intravenous urograms (IVU) are listed and in Table III those of 19 positive cystoscopies. It should be pointed out that in addition to these two investigations the patients had the following performed: full blood count and ESR, urea and electrolytes, serum creatinine and three early morning urines for acid fast bacillus exclusion. These were without exception normal.ọ Selection for renal biopsy was made on the advice of the $\vec{\omega}$ nephrologist at St Thomas' Hospital or at the Institute of Urology. It must be emphasised that other cases of

Table I

Findings in Patients age 8 to 40

Number of patients 90

Age range

Gross: microscopic haematuria

Exercise related

Known smoker $8-40$ $64: 26(71 \%: 29 \%)$

Positive physical findings

$19(21 \%)$

$32(35 \%)$

RBC's on microscopy on hospital MSU

IVU performed

$18(20 \%)$

$54(60 \%)$

$83(90 \%)$

Positive IVU

Cystoscopy performed

$11(13 \%)$

$75(83 \%)$

Positive cystoscopy

Renal biopsy performed $19(25 \%)$

Positive renal biopsy 5

Final Positive Diagnosis

4

$51(57 \%)$

Table II

IVU Positive Findings - II

*Stone at UO

${ }^{*}$ Retrocaval ureter

Dilated calyx on left

*Right hydronephrosis

Lateral displacement of kidney

Partial crossed renal ectopia

Distensible pelvis on right

*Stone in lower left calyx

*Stone in upper ureter

*Trabeculated bladder

Bifid right ureter

* Likely cause of haematuria. 


\section{Flow Chart for the Investigation of Haematuria}

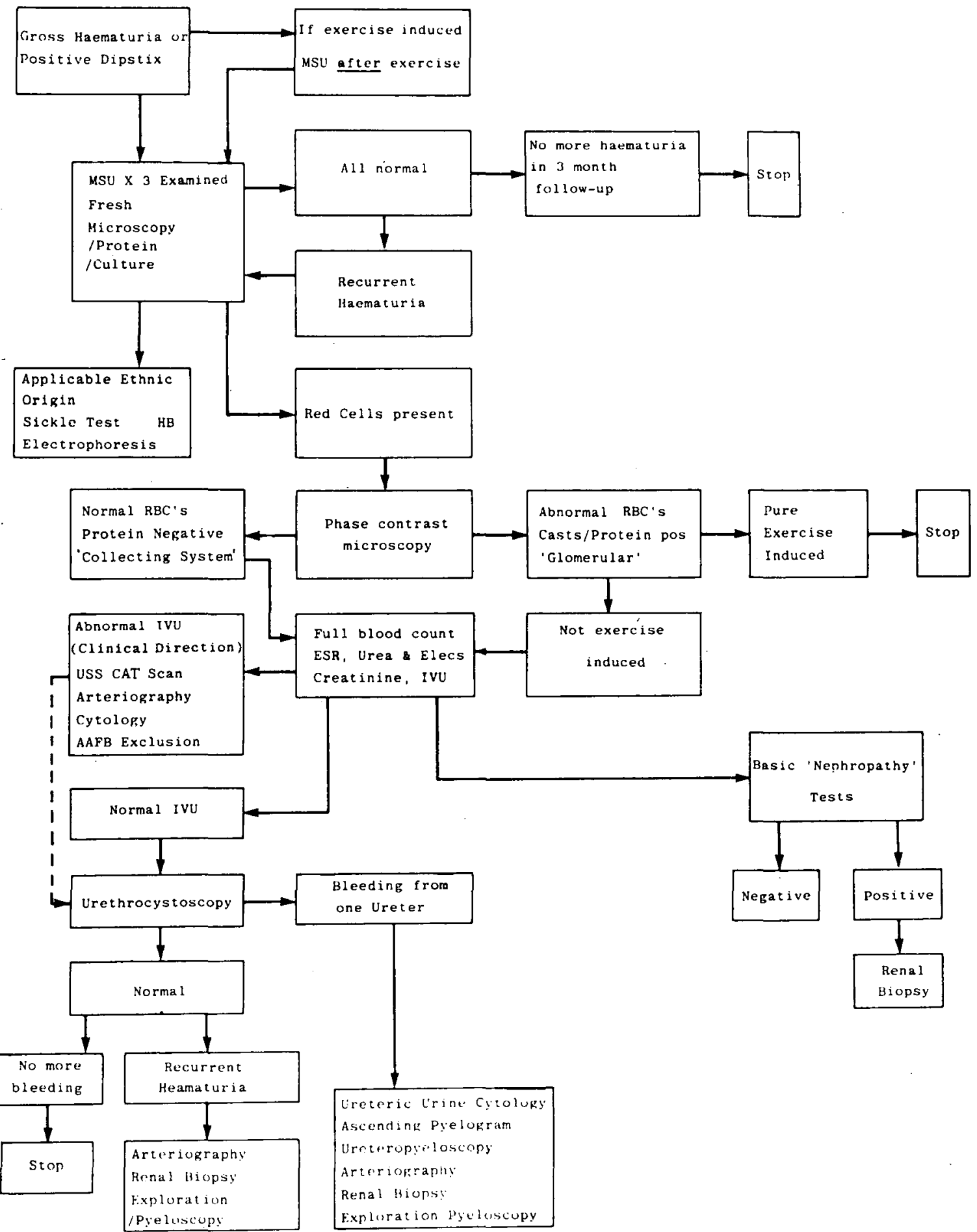


haematuria during this period will have been investigated and treated by our physician colleagues without referral to a urologist.

Table IV gives the positive final diagnoses.

Table III

Cytoscopy Positive Findings - 19

Bladder ecchymosis $\mathrm{x} 2$

Non-specific cystitis $x 4$

Abrasion at PS junction (? self-induced)

Tight urethra $\times 2$

Urethritis

Nodular protrate

Prostatic inflammation

Bladder neck polyp

Bladder neck hypertrophy

Bladder neck bleeding

TCC within bladder neck

'Worm' clots in bladder

Blood from LUO

Stone at LUO

Table IV

Positive Final Diagnosis - 51

Urinary stones (Kidney/ureter)

'Nephropathy' (IgA, Post-streptococcal, Glandular fever) 7

GU trauma in past

Lower tract inflammation (Cystitis, urethritis, prostatitis) 14

Minor trauma

Pure exercise induced

B-thalassaemia trait (Negro)

Crossed renal ectopia

TCC (Pis) of bladder

Bladder neck stenosis

Loin pain/haematuria syndrome

\section{Discussion}

There is no doubt that haematuria can be the first sign of a potentially life-threatening disease of the urinary tract $^{5}$. Previous series ${ }^{1,3,5}$ suggest that the under- 40 age group is considerably less at risk in this regard. The present study bears this out. However, investigation of the patient must be thorough enough reasonably to exclude serious pathology. In the Service this is not only important for the health of the patient but also for decisions on future employability.

The majority of the young people in this series, having been referred to a urologist, had the basic investigations? of MSU, blood count, serum biochemistry, IVU andos cystoscopy. Nine were subsequently referred for $\Rightarrow$ consideration of renal biopsy after full 'nephropathy's? screening, five biopsies being performed. Only $57 \%$ of the patients have a positive diagnosis (only five with a음 condition of any importance) even after such an investigation policy which includes an expensive $\mathrm{X}$-rayळ series and a general anaethetic.

The time has come for a generally agreed standard investigation procedure for all cases of isolated: haematuria' in the Service, which can be followed by $\vec{\omega}$ primary-care doctor, physician and surgeon. Such as procedure should cover all reasonable possibilities, butọ prevent the involvement of invasive, expensive or time- $\bar{?}$ consuming examinations where these can reasonably be expected to be non-contributory.

Confidence has been expressed ${ }^{6}$ in the reliability of phase-contrast microscopy in separating 'glomerule from 'collecting system' bleeding. We consider howe that the results do not yet justify basing investigation? decisions entirely on phase-contrast findings?

After discussion with all relevant authorities a investigation flow-chart ${ }^{8}$ as set out in the Figure $\mathrm{f}_{\mathrm{f}}^{\mathrm{s}}$ recommended for general adoption by the Arraye Medical Services.

\section{REFERENCES}

1. Greene, F L, O'Shaughnessy, E J and Hendricks, E B Study of five hundred patients with asymptomatic microhaematuria. JAMA 1956; 161: 610-613.

2. Carson, C C, Segura, J W and Greene, L F. Clinical $\mathbb{Q}$ importance of microhaematuria. JAMA 1979; 241: $149-150$.

3. Woodhouse, C R J. Microscopic haematuria. Br J Hosp Med 1982; pp 163-166.

4. Froom, P, RibaK, J and Benbassat, J. Significance of Microhaematuria. Br Med J 1984; 288: 20-22.

5. Carter, W C and Rous, $\mathrm{S} N$. Gross haematuria in $110 \widehat{3}$ adult urologic hospital patients. Urology 1981; XVIII: 342-344.

6. FAIRleY, K F and BIRCH, D F. Haematuria: A simple method for identifying glomerular bleeding. Kidney Int $\Phi$ $1982 ; 21 ; 105-108$.

7. JONES, N F. Personal communication, 1982.

8. ABuelo, J G. Evaluation of haematuria. Urology 1983; 음 XXI: $215-225$. 